\title{
Specialized home care for patients with AIDS: an experiment in Rotterdam, The Netherlands
}

\author{
Marian Moons MSc \\ Research Fellow \\ Ada Kerkstra PhD \\ Co-ordinator of Community Nursing Research, Netherlands Institute of Prmary Health, \\ Utrecht \\ and Tineke Biewenga MSc \\ Head of the Department of Psycho-Social Care, University Hospital of Rotterdam, \\ The Netherlands
}

MOONS M, KERKSTRA A \& BIEWENGA T (1994) Journal of Advanced

Nursing 19, 1132-1140

Specialized home care for patients with AIDS: an experiment in Rotterdam, The Netherlands

Patients with AIDS are permanently dependent on medical and technical nursing care Dunng a certain phase of the disease some of the patients have to visit the out-patient clinic of the hospital for regular treatment It was noticed that AIDS patients find these visits a severe burden Therefore in Rotterdam an experiment has been started to provide them the technical-medical and nursing care at home instead of at the out-patient clinic During the experiment, specialized hospital nurses visited the patients at home They worked in close collaboration with the community nurses An exploratory study was carried out to assess the prospects and difficulties of this new kund of home care for AIDS patients from a medical, psycho-social and organizational point of view The results suggested that it is possible to relocate the technical-medical and nursing care from the out-patient clinic to the patients' home This specialized home care is seen as desirable from the perspectives of the AIDS patients and informal and professional caregivers However, some organizational aspects, like the co-ordination and communication among caregivers and the avallability of the specialized hospital nurses during the weekend, must be improved in the future

\section{INTRODUCTION}

AIDS has been described as the greatest challenge to public health of our time (Beedham \& Wilson-Barnett

Correspondence Manan Moons, Netherlands Institute of Prmary Health Care (NIVEL) PO Box 15683500 BN Utrecht The Netherlands
1993) In the last decade, public health care and health care workers have been preparing for this new disease and its patients practical measures have been taken (gloves, needle-boxes) to reduce the risk of contagion Behaviour gudelines have been given, since it is in the nature of their jobs that health care workers will be 
exposed to potential infection while performing routine tasks They must be constantly aware that infection might come from an undiagnosed individual

As long as there is no effective treatment for AIDS avalable, the major part of the care which nurses are able to provide may be emotional support for patients and their relatives and good physical care (Robbins et al 1992) In this context Siminoff et al (1991) stated that AIDS challenges the ability of health care workers to provide competent and compassionate care to patients This ability to provide both the physical and emotional care needed may be hampered by the degree of knowledge and the attitudes of nursing staff (Robbins et al 1992) Findings from several studies among nursing staff reveal that there is limited knowledge about many aspects of AIDS (Bond et al 1990, Melby et al 1992, Plant \& Foster 1993) More important, however, is that nurses are concerned about their lack of experience and knowledge about HIV infection, and have reported insufficient professional support to enable them to work more effectively

\section{Meetung the challenge}

When AIDS poses a challenge to health care, a major part of meeting this challenge is to provide services which are responsive to the needs of those affected (Beedham \& Wilson-Barnett 1993) In this paper an example of such service will be described An experiment with specialized home care for patients with AIDS was started at the initiative of the out-patient department for internal mediane of the University Hospital of Rotterdam, The Netherlands This was done in close collaboration with the community nursing organization in Rotterdam

This experiment of relocating specialist care to the homes of the patients fits well into the moving patterns of care for patients with AIDS While the initial response to the epidemic came from health authorities in high prevalence areas and involved the setting up of specialist hospital care and hospital-based services, the emphasis of care is moving increasingly towards the community (Beedham \& Wilson-Barnett 1993) But because of the complexity of the disease and the relatively new and experimental treatment and medication, co-operation between specialized hospital care and community nursing care seems particularly significant According to Layzell \& McCarthy (1993), in the development from specialist to generic care, distinctions can be made among three types of home care for patients with AIDS, 'specialist HIV home support teams', 'clinical nurse specialist in HIV/AIDS' and 'generic community nursing care'

\section{THE EXPERIMENT IN ROTTERDAM}

Patients with AIDS are permanently dependent on medical and technical nursing care Durng a certain phase of the disease some of the patients have to visit the out-patient clinic of the hospital for regular treatment At the University Hospital of Rotterdam, it was noticed that, in general, AIDS patients find these visits (the journey, the warting time) a severe burden Presumably, these visits have a negative effect on their quality of life, they may even make admission to hospital inevitable To meet the needs of these patients with AIDS, an experiment has been started to provide them with appropriate care at home

Two physicians specialızing in internal medicine, and three hospital nurses specializing in the care for patients with AIDS, were part of the organization of the outpatient clinic for internal medicine The specialıst nurses also had the tasks of psycho-social counselling and educating the patient and his or her relatives about HIV infection (Academisch Ziekenhuss Rotterdam 1991)

Durnng the experiment the specialized hospital nurses visited the patients at home So, instead of going to the out-patient clinic, the participating patients received specialized home care The specialist who was in charge of the patient bore responsibility for the specialized home care A patient could only take part in the experment if the general practitioner did not object to the specialized home care Whenever necessary, this specialized nursing care was complemented by regular community nursing care

This could be seen as an experiment in 'transmural nursing care' for AIDS patients In this experiment, the hospital nurse and the community nurse worked in close collaboration to guarantee the continuty of care and the most convenient care for the patient Before the specialized care at the home of a patient started, the hospital nurse and the community nurse made the assessment visit together During the experiment the hospital nurse and the community nurse together bore responsibility for the co-ordination of the home care

\section{Protocols}

Protocols were drawn up for those technical-medical and nursing treatments normally given in the out-patient clinic and relocated within the framework of the expenment to the home of the patient Conditions, necessary facilities and procedures, as well as possible complications were described extensively in those protocols The necessary qualifications were also assigned for administenng each of the technical-medical and nursing treatments For 
Table 1 Relocated

technical-medical and nursing care and its required qualification
"Required qualification code $\mathrm{A}$ community nurse- code $B$, specalized nurse code $C$ the first tume done by physican, later delegated to specaalized nurse
Requrred level of qualification*

Takıng a culture

Taking a sputum-culture

Giving a blood transfusion (maximum 2 packed cells)

Adminstering pentamidine/ventolin by atomizer

Inserting an infusion (penpheral)

Admunistenng parenteral feeding by port-a-cath

Takıng blood sample by venapunction

Taking a blood culture (by venapunction)

Fixing a needle in port-a-cath

Code A

Code A

Code A

Code A

Administering medication by port-a-cath

Admunsterning clotting factors
Code B

Code B

Code B

Code B

Code B

Code C

Code $\mathrm{C}$ example, qualification treatments with code $A$ might be given by any nurse with basic training and also by a community nurse But for practical reasons the specialized hospital nurse might give these treatments during the experiment, because the cultures taken had to be analysed in the hospital laboratory An extra qualification was needed for treatment with code B Only nurses specializing in the care of AIDS patients were qualified to take part in this experiment Treatments with code $C$ could be given by a physician the first time and later delegated to a specialized nurse Table 1 gives an overview of the technical-medical and nursing treatments that were selected for relocation

It was only a small-scale exploratory experiment the maximum period of care was set, beforehand, at 6 months and about 10 patients in the neighbourhood of Rotterdam took part in the expenment

Patients qualified to take part in the experiment when, according to the classification of the Centers for Disease Control (WHO 1991), their HIV infection was in phase IV B, C or D and when therr Karnofsky Performance Score (Grieco \& Long 1984) equalled 60 (='Requires occasional assistance but is able to care for most of his or her needs') or less Patrents also had to meet some practical requirements in respect of housing (e g permanent address, telephone, bathroom) and the attendance of an informal caregiver

\section{Karnofsky Performance Score}

The first selection of potential participants was made by the medical team in the hospital The Karnofsky Performance Score was used as an indicator for the degree of care needed When the medical criterna were met and the patient was interested in the expenment, the specialized hospital nurse informed the patient about the practical requirements in respect of housing The attendance of an informal caregiver and the co-operation of the general practitioner were also discussed The patient, the informal caregiver and the general practitioner had to sign an informed consent form in which they also agreed to participate in an evaluation of the experiment

\section{EVALUATION}

An evaluation was part of the expenment The arm of this exploratory study was to assess the prospects and difficulties of this new knd of home care for AIDS patients from medical, psycho-social and organizational points of view More specifically, the evaluation attempted to find answers to the following questions

1 From a medical point of view, is it possible to relocate technical-medical and nursing treatment from the out-patient clinic to the home of the patient?

2 From a psycho-social point of view, what experience do the patients and the informal caregivers have of this kind of specialized nursing care?

3 From an organizational point of view, what expenence do the professional caregivers have? What is the best way to organize special home care for AIDS patients?

An attempt was made to evaluate the economic aspects of the relocation of specialized home care as well The results made it clear that analysing the costs of health care is a very complex process and that further study is necessary The results will not be presented here 


\section{METHOD}

\section{Sample}

Between March 1991 and September 199213 patients took part in the expenment Three of them did so in 1991 and the others in 1992 Owing to ill health and shortage of personnel the experiment had to be suspended from August 1991 through to January 1992

The average period of specialized home care received by the patients was 3 months The shortest period of care was only 16 days Only one patient received specialized home care for the maximum period of 6 months Three others took part in the experiment until the end of the project

Six patients died at home, three others had to be admitted to hospital or a nursing home Seven patients were admitted to hospital dunng the experiment after their discharge the specialızed home care was restarted

The age of the participating patients was between 27 and 60 years, and they were all males Four of the patients were living alone with an informal caregiver nearby Two patients were receiving informal care from their parents The other seven patients were living with their partners

\section{Instruments}

The following data have been collected to answer the three questions After each home visit the hospital and community nurses recorded all activities and tasks undertaken on a drary sheet They also kept records of the facilities used and the time spent on these activities $A$ logbook in the homes of the patients was used as a means of communication between the caregivers

On several occasions during the specialized home care, semi-structured interviews were held with the patient and with the informal caregiver In these interviews questions were asked about experience with the specialized home care These interviews were planned to take place after 1 . $3 \frac{1}{2}$ and 6 months of home care Soon after the start of the experiment this time schedule was seen to be infeasible After 1 month two patients had already died and two others had to be admitted to hospital Only a few of the participating patients were able to give an interview after $3 \frac{1}{2}$ and 6 months Only nine patient interviews (after 1 month) could be analysed for this evaluation

\section{Informal caregivers}

A similar interview and time schedule was set up for the informal caregivers Durng the experument the same time schedule problems emerged Because the informal caregivers were also interviewed after the death of the patient or after admission to hospital or a nursing home, more data were collected A total of 17 informal caregivers' interviews were analysed (seven after 1 month, 10 after ending the home care period)

After completion of the period of specialized home care for a patient, all professional caregivers involved in the experiment were sent a postal questionnaire They were asked about positive and negative expenence of specialized home care and of the co-ordination of care and the collaboration with other caregivers Data were collected from the general practitioner (10 times), hospital nurse (15 times) and community nurse (14 times) for most patients Sometimes more than one community or hospital nurse was involved in the home care

Below, attention is pard to the three aspects of the evaluation study, the medical, psycho-social and organizational aspects of specialized home care In other words, what care was given during the experiment and what the expenence of the receivers and providers was in respect of this new kind of care

\section{RESULTS}

\section{Technical-medical and nursing care}

The technical-medical care and nursing care that was offered in the homes of the patients durng this expenment consisted of a combination of relocated specialızed care and regular community nursing care

The average number of home visits by the specialized hospital nurses was nine per patient, with a range of two to 20 visits The average length of a visit wans $1 \frac{1}{2}$ hours, with a range of 25 minutes to 5 hours Only six of the 13 patients participating received regular or intensive care from the community nurse The average length of these home visits was 1 hour, with a range of 15 minutes to 2 hours When the duration of the penod of specialized home care is taken into account, the intensity of the care needed appears to be related to it those who particapated in the expenment for a relatively short penod needed more care from the specialized hospital nurses and the community nurses

\section{Specialized hospital nurses}

Table 3 gives an overview of the care given by the specialized hospital nurses Thurty-three per cent of the home visits involved the hospital nurse taking a blood sample by venapunction In $22 \%$ of the home visits medication was administered via a port-a-cath, and in $17 \%$ of the cases a needle was fixed in a port-a-cath 
Table 2 Home care by the specialized hospital nurse and the community nurse during the expenment

Table 3 Specialized home care by the specialized hospital nurse, absolute numbers and percentage of the total number of home visits $(n=117)$
Specialızed home care Community nursing care

$\begin{array}{lcc}\begin{array}{l}\text { Number of patients } \\ \text { Total number of home visits }\end{array} & 13 & 6 \\ \begin{array}{l}\text { Average number of home visits per patient } \\ \text { Average duration of home visits (minutes) }\end{array} & 90 \text { (range 2-20) } & 149 \\ \begin{array}{l}\text { Number of weekly home visits by length } \\ \text { of penod of specialized care }\end{array} & & 60 \text { (range 4-48) } \\ \quad & \\ \leq 1 \text { month } & 25 & 66 \\ 2-5 \text { months } & 07 & 42 \\ \geq 6 \text { months } & 05 & -120 \text { ) }\end{array}$

Absolute

number

$\%$

Special treatments

Taking a blood sample by venapunction $\quad 38 \quad 33$

Administerng medication by port-a-cath $\quad 24 \quad 22$

Fixing a needle in port-a-cath

Adminustening pentamidine/ventolin by atomizer

Inserting an infusion (penpheral)

Taking a culture

Giving a blood transfusion (maximum 2 packed cells)

Administering parenteral feeding by port-a-cath

Taking a sputum-culture

Taking a blood-culture by venapunction

Administerning clotting factors

Other

$\begin{array}{rr}20 & 17 \\ 6 & 5 \\ 4 & 3 \\ 4 & 3 \\ 3 & 3 \\ 2 & 2 \\ - & - \\ - & - \\ - & 7\end{array}$

Education

Information on treatment given $\quad 94 \quad 80$

Information on medication given $\quad 38 \quad 32$

Discussing the pressure the informal caregiver is subjected to 3933

$\begin{array}{lll}\text { Suggestions for possible additional professional care } & 21 & 18\end{array}$

Suggestions for possible admission to hospital/nursing home $\quad 10 \quad 9$

Suggestions for ways of adapting the house

2

3

Discussing the nsk of contagion with informal caregiver

Support

Acceptance of illness (patient)

32

Acceptance of lliness (informal caregiver)

37

Acceptance of death (informal caregiver)

Acceptance of death (patient)

Other
Some of the protocolled treatments were not administered at home taking a sputum-culture, taking a blood culture and administering clotting factors

The specialized care by the hospital nurses included more than technical-medical and nursing care They also provided health education and psycho-social support to the patients and informal caregivers durng the home visits In fact, in $23 \%$ of the home visits education and support were the main purpose of the visit This mostly concerned information on the treatment given $(80 \%)$ and 
Table 4 Community nursing care by the community nurse, absolute numbers and percentage of the total number of home visits $(n=149)$
Categones of care

Absolute

number

$\%$

Technical nursing care

136

Personal hygiene care

135

54

Support for informal caregivers

Health education (a) information

(b) stimulation and reassurance

Support for psycho-social problems

Household activities
91

91

36

30

15

26

17 on the medication used (32\%) (Table 3) The pressure the informal caregiver was subjected to', and 'the acceptance of the illness' were discussed in about one-third of the home visits (33-32\%) It was striking that virtually equal attention was given to the patient and informal caregivers After $40 \%$ of the home visits, the hospital nurses consulted specialists and, after $9 \%$ of the home visits, community nurses

\section{Communty nurses}

Community nurses focused on personal hygiene and technical nursing care of the patient (see Table 4) This was the case in more than $90 \%$ of the home visits, $1 \mathrm{e}$ prevention and care of pressure sores (80\%), making the bed $(43 \%)$, bathing $(85 \%)$, dressing $(57 \%)$ or moving the patient $(25 \%)$

Health education and support were also provided by the community nurses They spoke about the illness, complaints (together 20\%) and medication (8\%), about the acceptance of the 1 llness (12\%) and the burden of care for the informal caregiver $(26 \%)$

Unfortunately, there are no figures avalable on technical-medical and nursing care given by the specialized hospital nurses at the out-patient clinic Accordingly, the data presented here are meant more as an illustration of the specialized home care provided, rather than as reference material The care provided by the community nurse, on the other hand, can be compared to a Dutch national survey of community nursing care (VorstThujssen et al 1990) The participating patients with AIDS received more technical nursing care $(91 \%$ against $74 \%$ of the home visits) and more personal hygiene care $(91 \%$ against $62 \%$ ) than is generally provided by the community nurse More attention was also given to the informal caregiver (36\% against $27 \%$ ) When the length of the home visits (for those AIDS patients who did recelve care from the community nurse) is taken into account, there appears to be more simulanty with patients who receive termunal care 60 compared to 40 minutes)

\section{The experience of the patients and informal} caregivers

In general, the expenence of both the patient and the informal caregiver of specialized home care was positive Beforehand, the patients were asked about their motives in participating in the expenment Push as well as pull factors appeared to be important the motives below were mentioned most often

I won't have to travel to the out-patient clinic any more

I can stay in my own house with those close to me

During the experiment these aspects were also important The most positive influence of specialized home care appeared to be that their daily life was relatively less disturbed by the illness The influence of the home care on 'their confrontation with AIDS', 'therr living situation' and 'the number of people who come to visit the patient' was assessed as neutral

Generally, the patients were very satisfied with the quality of specialized nursing care and the amount of care they received In particular, the emotional support given by the hospital nurse was highly appreciated

I can discuss all my complaints at length

The impossibility of access to the specialized hospital nurse during the weekend was felt as a severe problem in the case of an emergency during the night or evening the patient still had to go to hospital One of the patients said

It should be possible to contact the specialized nurse 7 days a week

The patients did not feel able to judge the co-ordination of care between the internal medicine specialist and 
hospital nurse and between the hospital nurse and community nurse The communication between the specialist and general practitioner, on the other hand, was inadequate, according to four of the patients interviewed The general practitioner did not receive enough information about the illness and treatment Eight patients were regularly visited by their general practitioner, largely for social reasons This demonstrable interest was highly appreciated by the patients

The informal caregivers tended to subscribe to most of these opinions They appeared to be more positive about the co-ordination and co-operation of the home care The amount of care received was assessed very positively Some of them thought that several different professional caregivers were visiting the house was inconvenient for the patient None of the patients had any objections about it, however

About one-thurd of the informal caregivers did not find the penod of specialized home care too severe a burden One of them said

It gives you strength I could have continued for another 10 years

Others were a little less enthusiastic The majonty of the informal caregivers interviewed mentioned physical and psychological stress and lack of freedom durnng the penod of care

The expression 'meaningful' was used by most of them Despite everything it was worth it after all One of the relatives sard

In spite of everything, he was with us that became awfully clear after his death

\section{Experience of the professional caregivers}

Information about this aspect of the evaluation study came from 10 general practitioners (10 patients), three hospital nurses (13 patients) and from 14 different community nurses (10 patients)

\section{General practitioners}

The general practitioners visited eight of the 10 patients regularly durning the whole period of specialized home care In their view that meant twice to four times per month As regards the two other patients, the general practitioner only got involved in the home care at the end of the penod (around their death or admission to hospital/nursing home)

Eight general practitioners had had contact with the internal specialist Five of them had positive and three had negative expenences These last general practitioners were dissatisfied with the information they received (too little/illegible) on the health status treatment and medication of the patient and in particular on the date of discharge Six general practitioners had had contact with the specialized hospital nurse, usually by means of the logbook, by telephone or via the informal caregivers Two of them were enthusiastic about the collaboration The other four were more neutral Contact with the community nurse was also reported by six general practitioners All of them were very positively disposed They usually knew one another farly well

In the opinion of the general practitioners, the amount of care was sufficient Only one general practitioner recorded an undesirable situation for a patient because of an inaccurate procedure surrounding discharge

Their personal expenences were mainly positive and varied between 'rather taxing' and 'very instructive'

\section{Specialized hospital nurses}

All the hospital nurses were very positive about the contact with the internal specialist They were also positive about the collaboration with the general practitioner and the community nurse 'good' to 'neutral' One of the general practitioners appeared to be a bad reporter (who did not make use of the logbook), which resulted in extra work for the hospital nurse In the opinion of the hospital nurses, the assessment visits with the community nurse were very useful

In their opinion, the amount of care provided was sufficient at the beginning of each new specialized home care situation, it was even possible to make extra visits to the patients' home to reassure them

As less positive aspects they mentioned the situation during the weekend and at night the fact that it was impossible for the patient to get in contact with the hospital nurse placed an extra burden on the informal caregiver On two occasions, this led to an undesirable situation and an inevitable admission to hospital The three other undesirable situations reported occurred as a result of mistakes in the supply of materials and lack of co-ordination surrounding discharge from hospital

The personal expenence of the hospital nurses was mainly positive Aspects that did bring some discomfort were

when the patient expressed a wish for euthanasia

when a patient needs very intensive care, 3 hours a day for 2 weeks

when a patient passes away very soon after the start of care 


\section{Community nurses}

Eleven of the 14 community nurses reporting had had contact with the general practitioner they had all positive experiences

He was always avallable

Weekly contact, very pleasant co-operation

The opinions differed about the co-operation with the specialized hospital nurse Five community nurses were very positive about it, while five others were neutral One community nurse was dissatisfied She reported 'frequent changes in the hospital nurses and difficult contact'

In their opinion the amount of care provided was sufficient Most of them were very positive about the whole project $A$ few undesirable situations were reported

Patient suffered unnecessary pain because there was insufficient control of medication (and informal caregiver)

It was unclear who should fix the catheter

Their own expenences with the home care for patients with AIDS vaned between

Canng for an AIDS patient is as much a burden as canng for any other patient with a terminal disease

Caring for an AIDS patient is an extra burden because of the need for more education and support from relatives

In summary, the professional caregivers were positively disposed towards the option of specialized home care for AIDS patients It was thought to be a good opportunity to offer appropnate care at home Others judged that this kind of home care made a contribution to a more worthy, humane process of dying It was also concluded that the length of hospital stays decreased significantly, in particular for patients with a port-a-cath One of the general practitioners said

I should like this kand of care myself

\section{Problems}

In addition to positive remarks about this new form of health care delivery, a number of caregivers did also mention some problems Furst, co-ordination and communication among caregivers was not optimal in a number of respects General practitioners in particular felt that they were not sufficiently well-informed by the specialists When home care starts (or is restarted) it should be made clear who is responsible for what Community nurses say that, with respect to treatment, more explicit agreements should exist between primary health care and specialist medical care They also point to a certain amount of overlap, especially in the support of patients and informal caregivers A general lack of knowledge and experience with AIDS patients among community nurses is also mentioned as a problem

A second problem is the fact that a specialized hospital nurse is not avallable during the weekend This point was mentioned by nearly every patient, informal caregiver, general practitioner and communty nurse In case of emergency during the night or evening the patient still had to go to hospital, and some informal caregivers were overwhelmed by the responsibility for the well-being of the patient

Third, informal caregivers were heavily burdened though often at their own wish Extra help offered by the communty nurse was often rejected by the patient's relatives

Finally, during the expenment, it became clear that the supply of materials presented senous problems as well, especially in respect of timely delivery and reimbursement

\section{DISCUSSION}

The general conclusion which can be drawn on the basis of this experiment is that continuation of specialized home care for AIDS patients is seen as desirable from the point of view of the patients and informal and professional caregivers Furthermore, it has been shown that it is possible to relocate the technical-medical and nursing care from the out-patient clinic to the patients' home

Generally, it can be said that the changeable course of AIDS produces a lot of variation in the total amount of time patients need care, as well as in the frequency of care A number of patients in fact received terminal care Care for these patients was often intensive, they also received more regular community nursing care For others again, the expenment was an opportunity to retain a degree of independence much longer than normal The sometimes rapidly declining health situation of participating patients might have more to do with the avalable medication for AIDS patients than with the selection criteria of the experiment It seems that the experiment was especially relevant for patients with a port-a-cath $A$ considerable (5-13 day) decrease in length of hospital stay was registered for four of the five patients

Nevertheless, a number of problems have arisen, which should be dealt with in view of the continuation of this specialized home care in particular, the avallability of a 
specialized hospital nurse outside normal working hours The co-ordination of care and the communication between professional caregivers also caused problems

During the experiment it became more and more clear that, in addition to the relocated practical nursing care, support, counselling and co-ordination were important aspects of the care provided in $23 \%$ of the home visits by the hospital nurse, this was the main reason for the visit Health education and support were important aspects of the care given by the communty nurse as well Not only the patients but also the informal caregivers have an urgent need for education and support almost equal attention was given to both by hospital nurses These expenences in Rotterdam are in accordance with the expenence of the Home Support Team in inner London (Smits et al 1990) The avallability of this team (consisting of six specialized nurses, a general practitioner medical officer and a receptionist) out of hours to patients was a key part of the service Reasons for patients to contact the team out of normal working hours were, for instance, 'detenoration in condition $(40 \%)$ ' or 'need for advice and reassurance (25\%)' Patients perceived the role of the team largely in terms of offerng advice, social support and contacting other agencies for them

\section{Co-ordination of care}

In general, problems of co-ordination of care for patients with AIDS appears to be particularly acute between the hospital and community services and among the vanous agencies involved in providing community care (Beedham \& Wilson-Barnett 1993) During this exploratory expenment, co-ordination of care took place at an individual level sometimes the patient or the informal caregiver co-ordinated the care themselves General practitioners' involvement in co-ordination of home care seemed to vary with his or her contact with the patient and his or her interest in AIDS The development of a more structural kand of co-ordination is highly desirable

To ensure effective communication between the professional caregivers, it would seem important to have a co-ordinated assessment visit by the hospital nurse and community nurse together and to promote effective communication by means of a logbook at the home of the patient

This experiment in Rotterdam could be classified as a 'specialıst' model of care (Layzell \& McCarthy 1993) For the future, takıng into account the increasing incidence of HIV and growing demand for home care, another model of care in which extra attention is paid to co-ordinating and supporting tasks, might be more appropriate

\section{References}

Academisch Ziekenuis Rotterdam (1991) Protocol Voor de Behandeling en Begelerding oan met het Humaan Immunodeficientie Virus Geinfecteerde Patienten Deel I Organisatie van de Zorg Academisch Ziekenhuus Rotterdam, AIDS-commissie, Rotterdam

Beedham HM \& Wilson-Barnett J (1993) Evaluation of services for people with HIV/AIDS in an inner-city health authonty perspectives of key service providers Journal of Advanced Nursing 18, 69-79

Bond S, Rhodes T, Phillips P \& Tierney A (1990) Knowledge and attitudes, HIV-infection and community nursing staff in Scotland (2) Nursing Times 86(45), 49-51

Gneco A \& Long CJ (1984) Investigation of the Karnofsky Performance Status as a measure of quality of life Health Psychology 3(2), 129-142

Layzell S \& McCarthy M (1993) Specialistic or genenc community nursing care for HIV/AIDS patients? Joumal of Adoanced Nursing 18, 531-537

Melby V, Boore JRP \& Murray M (1992) Acquired ummunodeficiency syndrome knowledge and attitudes of nurses in Northern Ireland Journal of Adoanced Nursing 17, 1068-1077

Plant ML \& Foster J (1993) AIDS-related expenence, knowledge, attitudes and beliefs amongst nurses in an area with a high rate of HIV-infection Journal of Adoanced Nursing 18 , 80-88

Robbins I, Cooper A \& Bender MP (1992) The relationshup between knowledge, attitudes and degree of contact with AIDS and HIV Joumal of Advanced Nursing 17, 198-203

Siminoff L A, Erlen J A \& Lidz CW (1991) Stigma, AIDS and quality of nursing care state of the science Joumal of Adoanced Nursing 16, 262-269

Smits A, Mansfield S \& Singh S (1990) Facilitating care of patients with HIV infection by hospital and primary care teams British Medical Journal 300, 241-242

Vorst-Thissen $T$, van den Bnnk-Muinen A \& Kerkstra A (1990) Het Werk van Wijkverpleegkundigen en Wijzekenverzorgenden in Nederland NIVEL, Utrecht

WHO (1991) Statement on the Adoption of the Proposed Centre for Disease Control Case Defintion of AIDS European Centre for the Epidemiological Monitoring of AIDS, Saint-Maunce, France 
This document is a scanned copy of a printed document. No warranty is given about the accuracy of the copy. Users should refer to the original published version of the material. 